\title{
Isolated Rupture of Corpus Spongiosum Associated a Partial Rupture of the Urethra during a False Step of the Coitus: A Case Reported at the University Hospital Sanou Souro
}

\author{
Zakari Nikièma', Abdoul Karim Paré2, Clotaire Alexis Marie Kiemdida Donega Yaméogo33, \\ Adama Ouattara ${ }^{2}$, Ida Aida Tankoano ${ }^{1}$, Dominique Bicaba', Brahima Kirakoya ${ }^{3}$, \\ Timothé Kambou ${ }^{2}$, Rabiou Cissé ${ }^{4}$ \\ ${ }^{1}$ Medical Imaging Unit, Souro Sanou University Teaching Hospital, Bobo-Dioulasso, Burkina Faso \\ ${ }^{2}$ Urology Unit, Sourosanou United University Hospital, Bobo-Dioulasso, Burkina Faso \\ ${ }^{3}$ Urology Unit, Yalgado Ouédraogo United University Hospital, Ouagadougou, Burkina Faso \\ ${ }^{4}$ Medical Imaging Unit, Yalgado Ouedraogo University Teaching Hospital, Ouagadougou, Burkina Faso \\ Email: nikiemazakari@yahoo.fr
}

How to cite this paper: Nikièma, Z., Paré, A.K., Yaméogo, C.A.M.K.D., Ouattara, A., Tankoano, I.A., Bicaba, D., Kirakoya, B., Kambou, T. and Cissé, R. (2017) Isolated Rupture of Corpus Spongiosum Associated a Partial Rupture of the Urethra during a False Step of the Coitus: A Case Reported at the University Hospital Sanou Souro. Open Journal of Radiology, 7, 143-149. https://doi.org/10.4236/ojrad.2017.72016

Received: April 8, 2017

Accepted: June 19, 2017

Published: June 22, 2017

Copyright (c) 2017 by authors and Scientific Research Publishing Inc. This work is licensed under the Creative Commons Attribution International License (CC BY 4.0).

http://creativecommons.org/licenses/by/4.0/

\section{cC (i) Open Access}

\begin{abstract}
Penile fracture is a rare urological emergency. It occurs mainly in young adults during sexual intercourse. In many instances, one of the corpora carvanosus is involved though bilateral injuries with or without corpus spongiosus involvement is not uncommon. However, isolated injury to corpus spongiosus is extremely rare. We report a case of isolated rupture of corpus spongiosum secondary to penile injury during coitus in a 43-year-old man that presented to University Hospital Souro Sanou of Bobo Dioulasso. He presented with history of persistence bleeding per urethra following penile injury during sexual intercourse. The Retrograde urethrography (RUG) showed a partial rupture of urethra, Moore type 3. Complementary penile ultrasound revealed extensive contusion of the urethra with circumferential hematoma and rupture of the distal $1 / 3$ of the corpus spongiosus. He had gentle per urethral catheterization which was left for one month. Penile ultrasound sound done after removal of catheter showed residual injury and narrowing of the urethra.
\end{abstract}

\section{Keywords}

Penile Fracture, False Steps of Coitus, Rupture of Corpus

Spongiosum, Urethra Injury, Ultrasound 


\section{Introduction}

Penile fracture is a rare urological emergency, defined as a traumatic rupture of the tunica albuginea of corpus cavernosum during sexual intercourse most time [1] [2]. Bleeding per urethra indicates rupture of the spongiosum urethra. Rupture of the urethra during penile fracture depends on the extent of the injury. The isolated rupture of corpus spongiosum is very rare but described entity. It is often accompanied by a rupture of the urethra which surrounds it [3] [4]. Doppler ultrasound allows good characterization of the lesion [5] [6], guide treatment and monitoring of possible complications. We report a case of isolated rupture of corpus spongiosum as a result of penile injury during sexual intercourse.

\section{Case Report}

A 43-year-old businessman, married with three children, was referred to our institution with one week history of persistence bleeding per urethra following accidental injury to the penis during sexual intercourse. He sustained the trauma by hitting his erect penis on his partner's pubic bone. There was history of sharp sound and pain with subsequent bleeding per urethra after ejaculation. Since then he has been having painless bleeding per urethra. No change of penile curvature during erection. No history of a lower urinary tract symptoms, pelvic surgery or venereal disease. He was seen at a peripheral hospital where he was given Iron and Dicynone tablets. He was subsequently referred to the urology department of our institution for better care.

Clinical examination revealed a normal penis with active bleeding per urethra. Other findings were normal. A diagnosis of post traumatic penile fracture with concomitant urethral injury was made.

Hemoglobin and renal function were normal. Retrograde urethrogram (RUG) and Voiding cystouretrogram showed a partial rupture of urethra type 3 of the Moore classification (Figure 1) with extravasation of contrast into corpus spongiosum, suggesting a spongio-urethral partial rupture.

Complementary ultrasound confirmed an extensive contusion of the urethra with circumferential hematoma and rupture of the distal part of the corpus spongiosum with two deep laceration (Figure 2).

Magnetic resonance imaging could not be performed.

Patient had urethral catheterization which was left for one month. He was also placed on antibiotic.

Repeat ultrasound examination of the penis after removal of urinary catheter showed some narrowing of the urethra and parietal irregularities (Figure 3 and Figure 4).

\section{Discussion}

Penile fracture is a rare urological emergency. It is commonly seen in young men between 20 to 50 years old. It is almost exclusively occurs during sexual intercourse. It has been linked especially to vigorous sexual intercourse at this 

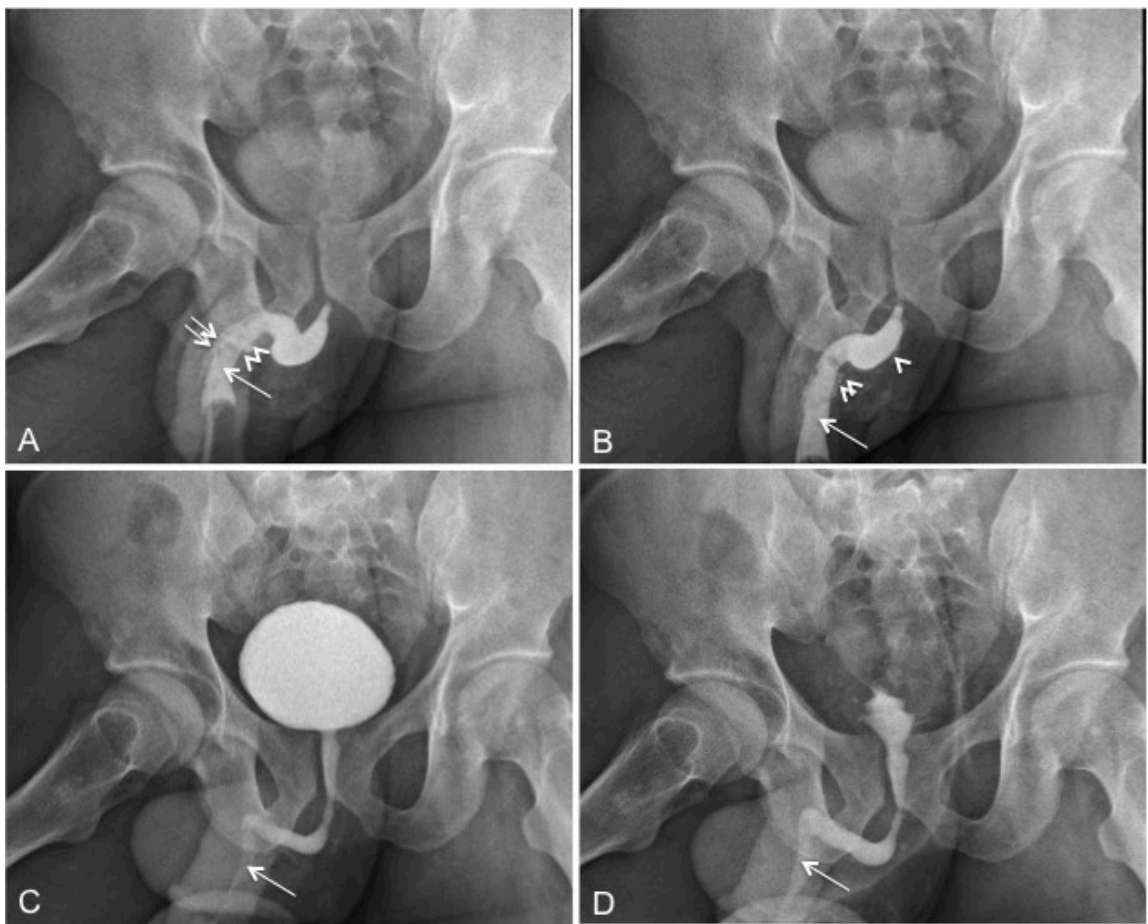

Figure 1. Uretrocystographie retrograde in a patient of 43 years. Highlight pseudo-lacunarimages ((A), (B), (C), (D), arrow) persist with opacification of Cooper glands ((A), (B), arrow head) and Littré ((A), (B), double arrow head) showing a partial rupture of urethra type 3 of Moore classification. He joined of contrast agent in spongy body ((A), double arrow), referring to a partial spongio-urethral rupture. (A), (B), (C), (D): longitudinal cuts.
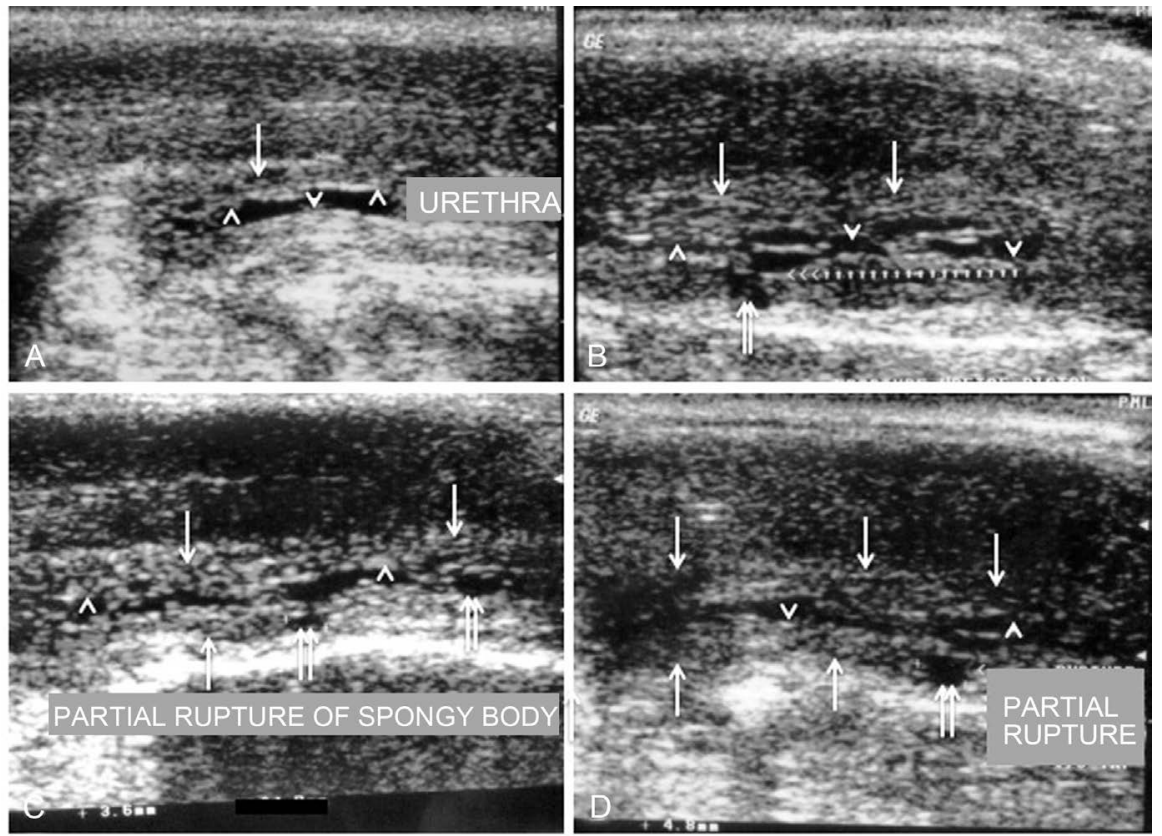

Figure 2. Rod ultrasound of the same patient. It shows urethra walls irregularities with duplication ((A), (B), (C), (D), arrow head), a circumferential hematoma ((A), (B), (C), (D), arrow) and two deep diverticula of distal 1/3. ((B), (C), (D), double arrow) witnessing spongy body fracture associated without impairment of the cavernosa bodies. (A), (B), (C), (D): longitudinal cuts. 


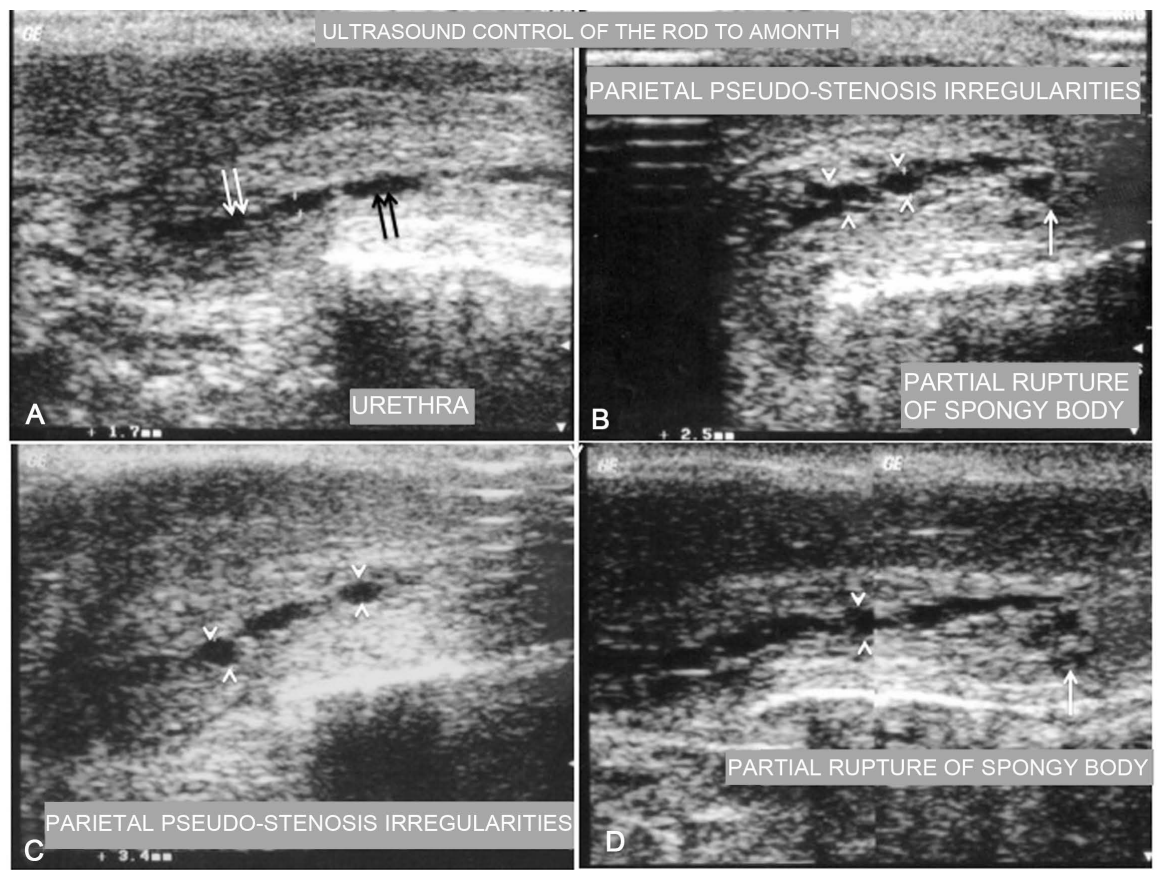

Figure 3. Ultrasound control of the rod to a month of the urinary catheter ablation. Persistence of parietal pseudo-stenosis irregularities ((B), (C), (D), arrow head) investor the $1 / 3$ superior $((A)$, double arrow). Also note the persistence of the focused partial rupture of distal 1/3 of spongy body ((B), (D), arrow). (A), (B), (C), (D): longitudinal cuts.

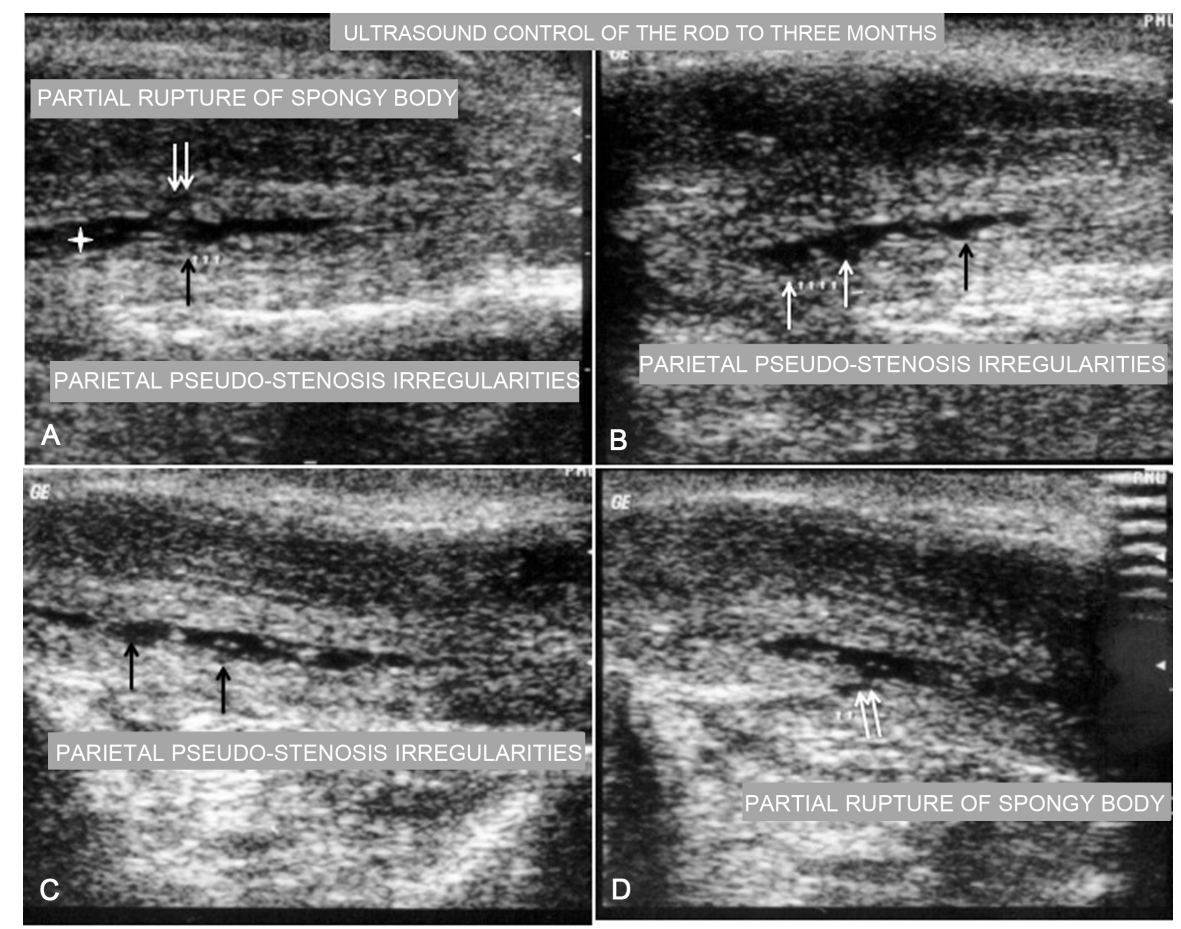

Figure 4. Ultrasound control of the rod to three months of the urinary catheter ablation. Persistence of parietal pseudo-stenosis irregularities ((A), (B), (C), arrow) and partial rupture of distal 1/3 of spongy body ((A), (D), double arrow). (A), (B), (C), (D): longitudinal cuts.

age. The most common cause is false step of coitus. In this index case, the pa- 
tient during sexual intercourse hit his erect penis on the pubic symphysis of his partner. This situation occurs when the penis slips out of the vagina during the sexual act [5].

The diagnosis of penile fracture is clinical after careful evaluation. Common presentation is penile pain at time of injury followed by penile swelling and later penile deformity on erection. It is a rupture of the tunica albuginea of the corpora cavernosa that is seen in most of the cases.

Bleeding per urethra indicates rupture of the spongiosum urethra. Rupture of the urethra during penile fracture depends on the extending of the injury. It is much more frequent in patient with bilateral fracture of the corpora cavernosa [7] [8]. In Africa and the Middle East, its incidence ranges from $0 \%$ to 15\% [5] [8], and in the United States of America and Europe, the incidence varies from $10 \%$ to $38 \%$ [9] [10].

An isolated rupture of corpus spongiosum without concomitant injury to the corpus cavernosum is very rare but it should not be ignored [4].

The place and choice of imaging in suspected penile fracture is controversial. Different modalities are used alone or in combination, including doppler ultrasound, retrograde urethrocystography, magnetic resonance imaging (MRI), cavernosography, angiography that will allow optimal characterization of injury, which may guide treatment, allow proper follow-up and early detection of complications [11] [12]. Among these imaging techniques, Doppler ultrasound is the first-line examination due to its safety, availability and low cost. However, it is highly operator dependent [6] but when conducted by experienced persons, it allows good characterization of the lesion [6] [13] [14], it also assist in follow-up and monitoring of possible complications. It was used in the index case when there was no satisfactory conclusion from RUG. However, RUG has a place in urethral trauma to categorized injuries based on Moore classification. Indeed, it has allowed in the index case our observation to pick the partial rupture of urethra.

MRI is usually carried out as second line of investigation when Doppler ultrasound is inconclusive. In fact, it gives precise extend, location and nature of injury to the tunica albuginea of corpus cavernosum as well as associated injury to corpus spongiosum or urethra. Its limitation includes high cost and non- availability in many centers.

Post-therapeutic penile ultrasound demonstrated persistence of suspected signs of moniliform uretral stricture. This shows the importance of this technique.

\section{Conclusion}

The rupture of the tunica albuginea of the corpus cavernosum of the penis is a rare pathology occurring most often in the young men during a sexual intercourse. Isolated injury to corpus spongiosum and urethra is extremely rare. Imaging especially Doppler ultrasound scan of the penis plays a major role in the evaluation and follows up of these patients. Our case report highlights the im- 
portance of Doppler ultrasound in cases of rupture of the tunica albuginea of the corpus cavernosum of the penis where the degree of clinical suspicion is high for an associated injury.

\section{Conflict of Interest}

None.

\section{Authors' Contribution}

All the authors contributed to the research work. The read and agreed to the final version of the manuscript.

\section{References}

[1] Phillips, E.A., Esposito, A.J. and Munarriz, R. (2015) Acute Penile Trauma and Associated Morbidity: 9-Year Experience at a Tertiary Care Center. Andrology, 3, 632 636. https://doi.org/10.1111/andr.12043

[2] Grima, F., Paparel, P., Devonec, M., Perrin, P., Caillot, J.L. and Ruffion, A. (2006) Prise en charge des traumatismes des corps caverneux du pénis. Progrès en Urologie, 16, 12-18.

[3] Bertero, E.B., Campos, R.S. and Mattos Jr., D. (2000) Penile Fracture with Urethral Injury. Brazilian Journal of Urology, 26, 295-297.

[4] Barolia, D.K., Sethi, D., Rana, V.K., Sethi, A. and Rachhoya, P. (2016) Isolated Corpus Spongiosum and Urethral Injury during Sexual Intercourse: A Rare Case. International Journal of Innovations in Medical Education and Research, 2, 64-66.

[5] Hinev, A. (2000) Fracture of the Penis: Treatment and Complications. Acta Medica Okayama, 54, 211-216.

[6] Cerone, J.S., Agarwal, P., McAchran, S. and Seftel, A. (2006) Penile Fracture with Isolated Corpus Spongiosum Injury. International Journal of Impotence Research, 18, 218-220. https://doi.org/10.1038/sj.ijir.3901389

[7] Nawaz, H., Khan, M., Tareen, F.M. and Khan, S. (2010) Penile Fracture: Presentation and Management. Journal of the College of Physicians and Surgeons Pakistan, $20,331-334$

[8] Nathan, A.H., Kiara, H.E. and Alan, S. (2011) Penile Fracture with Bilateral Corporeal Rupture and Complete Urethral Disruption: Case Report and Literature Review. Canadian Urology Association Journal, 5, 23-26.

[9] Jack, G.S., Garraway, I., Reznichek, R. and Rajfer, J. (2004) Current Treatment Options for Penile Fractures. Reviews in Urology, 6, 114-120.

[10] Hussein, M.A. (2012) Role of Early Surgical Repair of Penile Fractures. Iraqi Postgraduate Medical Journal, 11, 330-335.

[11] Karadeniz, T., Topsakal, M., Ariman, A., Erton, H. and Basak, D. (1996) Penile Fracture: Differential Diagnosis, Management and Outcome. British Journal of Urology International, 77, 279-281. https://doi.org/10.1046/j.1464-410X.1996.86420.x

[12] Pruthi, R.S., Petrus, C.D., Nidess, R. and Venable, D.D. (2000) Penile Fracture of the Proximal Corporeal Body. Journal of Urology, 164, 447-448. https://doi.org/10.1016/S0022-5347(05)67386-7

[13] Hoekx, L. and Wyndaele, J.J. (1998) Fracture de verge: Intérêt de l'échographie dans la localisation de la fracture du corps caverneux. Actualité d Urologie Belge, 66, 23 
25.

[14] Choi, M., Kim, B., Ryu, J.A., Lee, S.W. and Lee, K.S. (2000) MR Imaging of Acute Penile Fracture. RadioGraphics, 20, 1397-1405.

https://doi.org/10.1148/radiographics.20.5.g00se051397

Submit or recommend next manuscript to SCIRP and we will provide best service for you:

Accepting pre-submission inquiries through Email, Facebook, LinkedIn, Twitter, etc. A wide selection of journals (inclusive of 9 subjects, more than 200 journals)

Providing 24-hour high-quality service

User-friendly online submission system

Fair and swift peer-review system

Efficient typesetting and proofreading procedure

Display of the result of downloads and visits, as well as the number of cited articles Maximum dissemination of your research work

Submit your manuscript at: http://papersubmission.scirp.org/

Or contact ojrad@scirp.org 